\title{
Towards a research pole in photonics in Western Romania
}

\section{Virgil-Florin Duma, Meda Negrutiu, Cosmin Sinescu, Mihai Rominu, Eftimie Miutescu, et al.}

Virgil-Florin Duma, Meda L. Negrutiu, Cosmin Sinescu D.D.S., Mihai Rominu M.D., Eftimie Miutescu M.D., Amelia Burlea M.D., Miomir Vlascici, Nicolae Gheorghiu, Octavian Cira, Gheorghe Hutiu, Corina Mnerie, Dorin Demian, Corina Marcauteanu M.D., Florin Topala M.D., Jannick P. Rolland, loana Voiculescu, Adrian Gh. Podoleanu, "Towards a research pole in photonics in Western Romania," Proc. SPIE 9289, 12th Education and Training in Optics and Photonics Conference, 928916 (17 July 2014); doi: 10.1117/12.2070787

EDent: 12th Education and Training in Optics and Photonics Conference, 2013, Porto, Portugal 


\title{
Towards a Research Pole in Photonics in Western Romania
}

\author{
Virgil-Florin Duma $^{* a}$, Meda L. Negrutiu ${ }^{1 b}$, Cosmin Sinescu ${ }^{\mathrm{b}}$, Mihai Rominu ${ }^{\mathrm{b}}$, \\ Eftimie Miutescu ${ }^{2 \mathrm{c}}$, Amelia Burlea ${ }^{\mathrm{c}}$, Miomir Vlascici ${ }^{3 \mathrm{~d}}$, Nicolae Gheorghiu $^{\mathrm{e}}$, Octavian Cira ${ }^{\mathrm{a}}$, \\ Gheorghe Hutiu ${ }^{\mathrm{a}}$, Corina Mnerie ${ }^{\mathrm{a}}$, Dorin Demian ${ }^{\mathrm{a}}$, Corina Marcauteanu ${ }^{\mathrm{b}}$, Florin Topala ${ }^{\mathrm{b}}$, \\ Jannick P. Rolland $^{4 \mathrm{f}}$, Ioana Voiculescu ${ }^{\mathrm{g}, \mathrm{a}}$, Adrian Gh. Podoleanu ${ }^{\text {5h }}$ \\ a 3OM Optomechatronics Group, Aurel Vlaicu University of Arad, 77 Revolutiei Ave., Arad 310130, \\ Romania \\ ${ }^{\mathrm{b}}$ School of Dentistry, Victor Babes Medicine and Pharmacy University of Timisoara, 2A Eftimie \\ Murgu Place, 300070 Timisoara, Romania \\ ${ }^{c}$ Arad County Emergency University Hospital, 1 Calea Victoriei, Arad, Romania \\ ${ }^{\mathrm{d}}$ S.C. Inteliform S.R.L., 21 Calea Mosnitei, 300547 Timisoara, Romania \\ ${ }^{\mathrm{e}}$ S.C. Bioclinica S.A., 53B Cetatii Ave., Timisoara \\ ${ }^{\mathrm{f}}$ Institute of Optics, University of Rochester, 275 Hutchison Rd., Rochester, NY 14627-0186, USA \\ ${ }^{g}$ City College Nanofabrication Facility, Mechanical Engineering Department, City University of \\ New York, 140th Street \& Convent Avenue, New York, NY 10031, USA \\ ${ }^{\mathrm{h}}$ School of Physical Sciences, University of Kent, Canterbury, CT2 7NH, U.K.
}

\begin{abstract}
We present our efforts in establishing a Research Pole in Photonics in the future Arad-Timisoara metropolitan area projected to unite two major cities of Western Romania. Research objectives and related training activities of various institutions and groups that are involved are presented in their evolution during the last decade. The multi-disciplinary consortium consists principally of two universities, UAVA (Aurel Vlaicu University of Arad) and UMF (Victor Babes Medicine and Pharmacy University of Timisoara), but also of the Arad County Emergency University Hospital and several innovative SMEs, such as Bioclinica S.A. (the largest array of medical analysis labs in the region) and Inteliform S.R.L. (a competitive SME focused on mechatronics and mechanical engineering). A brief survey of the individual and joint projects of these institutions is presented, together with their teaching activities at graduate and undergraduate level. The research Pole collaborates in R\&D, training and education in biomedical imaging with universities in USA and Europe. Collaborative activities, mainly on Optical Coherence Tomography (OCT) projects are presented in a multidisciplinary approach that includes optomechatronics, precision mechanics and optics, dentistry, medicine, and biology.
\end{abstract}

Keywords: Research pole, photonics, training, optical coherence tomography, optomechatronics, optical devices, optical metrology, dentistry, laser treatments, gastroenterology, manufacturing, precision mechanics, micro-mechanics.

\section{INTRODUCTION}

Optics has always been a fascinating domain to approach, as light is a major component of human life. Thus, light and vision to begin with, then instrumentation and nowadays Photonics with so many applications hardly to present in this limited space represent fields that no scientist can miss.

The path towards an optics education and why not a career, has at least three possible starting points: Physics, Electrical and Mechanical Engineering. Of course, these are not exclusive, as Biology and Medicine are also now very much into this equation, as we shall see in this presentation as well.

\footnotetext{
* Corresponding author: dumavirgil@,osamember.org; phone 40-751-511451; site www.3omgroup.appspot.com/

${ }^{1}$ meda_negrutiu@yahoo.com; phone 40-722-700593

2 emiutescu@yahoo.com; phone 40-733-676881

3 mv@,inteliform.ro; phone 40-744-620628; site www.inteliform.ro/

4 rolland@optics.rochester.edu; site http://www.odalab-spectrum.org/Rochester/People.html

${ }^{5}$ A.G.H.Podoleanu@kent.ac.uk; phone +44.122.7 82.3272; site www.ac.uk/physical-sciences/research/aog/
} 
Fine (or precision) mechanics has been particularly dedicated to optics education \& research in Romania. While in the capital city of Bucharest it started in what is now UPB - the „Politehnica” University of Bucharest, in the Western (industrialized) part of the country this developement was mirrored some years later, when this domain was opened at what is now UPT - the „Politehnica” University of Timisoara, in close connection with industry development, IOT (Optical Entreprise Timisoara). This started as a branch of IOR (The Romanian Optical Entreprise), the „mother” company in Bucharest.

Both industry, education and R\&D in Fine Mechanics and Optics flourished until the 1989 Revolution changed conditions again. Communism fell and democracy (with the specific transition towards it) was installed; universities developed freely trying to find their place in a society that was itself rapidly (and sometimes chaotically) changing. In a few years only, the „big” centralized (state) industry fell and SMEs (Small and Medium Entreprises) took over the void left places. Technical universities had to make efforts to adapt, as until then, the engineering education and R\&D activities (with their related funding) were being carried out in relationship with the „big” industry. In parallel, the number of related State Research Institutes has also decreased considerably in the 90s.

Research Grants begun in 1998 (but a National R\&D Plan was issued only in 2002) to replace the old centralized system of contracts that was in place between industry, universities, and research institutes before 1989 (while some of the former Institutes' staff was naturally ,absorbed” by universities). SMEs have also grown in the meanwhile. Thus, a new, at first timid development began for the universities and for the related industry, after more than a decade of searches for a new system to fit in, this happened not only for the technical universities, but also for those which had only some departments focused on STEM - Science, Technology, Engineering and Mathematics. The EU (European Union) integration process that started in 2004 gave a boost to this process. Romania's integration in the EU in 2007 accelerated it, although the poor use of the available EU funding was - and still is - a shortcoming that affects it seriously. So did the economic crises that, we may say, stopped the growth of both industry and universities for several years. Funding has been unusually abundant for 3-4 years (although the 1\% of the National Product for Research, agreed with the EU, had not yet been reached). Then Europe entered into an economic crisis and the National Calls stopped for about 2 years. Priorities had to be set, which forced a new national Law of Education (and adjacent legislation) that lead to a much better (and long awaited) attention to be paid to competitiveness and real value. This also created premises for increased transparency in the system and set new, higher, more Western standards in promotion in both the universities and R\&D sectors. Conditions were created for research grants to be awarded on true competitive grounds. The process is yet incomplete, as two obvious tendencies still manifest: the first one is to push the reform further, in all its ethical and efficiency aspects, while a second one is to go back to a system not awarding the best and prone to intervention.

In Optics, the domain has very much followed the general trend, in universities, R\&D and industry. Thus, now there are several favorable conditions that are facilitating our initiative to establish a Photonics Pole in Western Romania, bringing together groups and institutions willing to participate:

(a) There is a strong tendency towards Photonics, Optomechanics and Optomechatronics developments in the area (coupled with the one at an international level), in conjunction with inter-disciplinary approaches, that include by example different areas of medicine;

(b) There is a process of significant growth of Romanian universities, with developing links with universities in Europe (especially after Romania joined the EU), but also in the US and in other parts of the world.

(c) The new project of Romanian regions and with the long time planned metropolitan area that is designed to unite the two major cities in Western Romania, Arad and Timisoara (which are less that $50 \mathrm{~km}$ apart), make the project of this Photonics Pole in the region more feasible;

(d) It is necessary to develop both the R\&D capabilities of the universities (and a stronger competition now exist between them in this direction), of the companies (and there are competion calls on EU funding in this specific direction), as well as of their collaborative links.

To follow these strategic lines, we have proposed and are currently working on a Partnership Project (1682/2011), funded by the Romanian Authority for Scientific Research - project that has several months of implementation now. It includes five institutions (Fig. 1) focused on different domains, in a complementarity that is intended to be the basic structure of the future Photonics Pole, as we shall present in the following. The links with other national and international collaborators will also be presented, as an intensification of these interaction is an essential part of our strategy. 
All these aspects raise specific issues that need to be solved, and this presentation points out some of our collaborative efforts to:

(i) achieve high quality research, with international impact;

(ii) direct the training of postgraduate (PG) students towards the most challenging and rewarding topics - while providing them with the proper international standards - for both research and publishing;

(iii) interact in a productive way with the industry and satisfy their demands - mainly on a national and regional level (which is an on-going demand, as pointed out previously);

(iv) shape the undergraduate students (UG) curricula to sustain the goals presented above, while also providing them with the basic knowledge to be able to be integrated in their professional environment, but in an innovative and thus competitive way. This is a major scope of the activity regardless of the area of the students (as in our Consortium we have both UG and PG students from areas as diverse as Mechanical Engineering, Automation, Medicine and Dentistry).

(v) interact with research active institutions abroad that can inspire and educate the staff of the Pole.

As one may remark, our approach is top-down, from the highest output, in R\&D (and its requirements), to the very basic aspects of higher education. Thus, the scope of this paper is to present the challenges we are facing and some of our solutions for achieving these goals.

\section{ACADEMIC AND INDUSTRIAL PARTNERS}

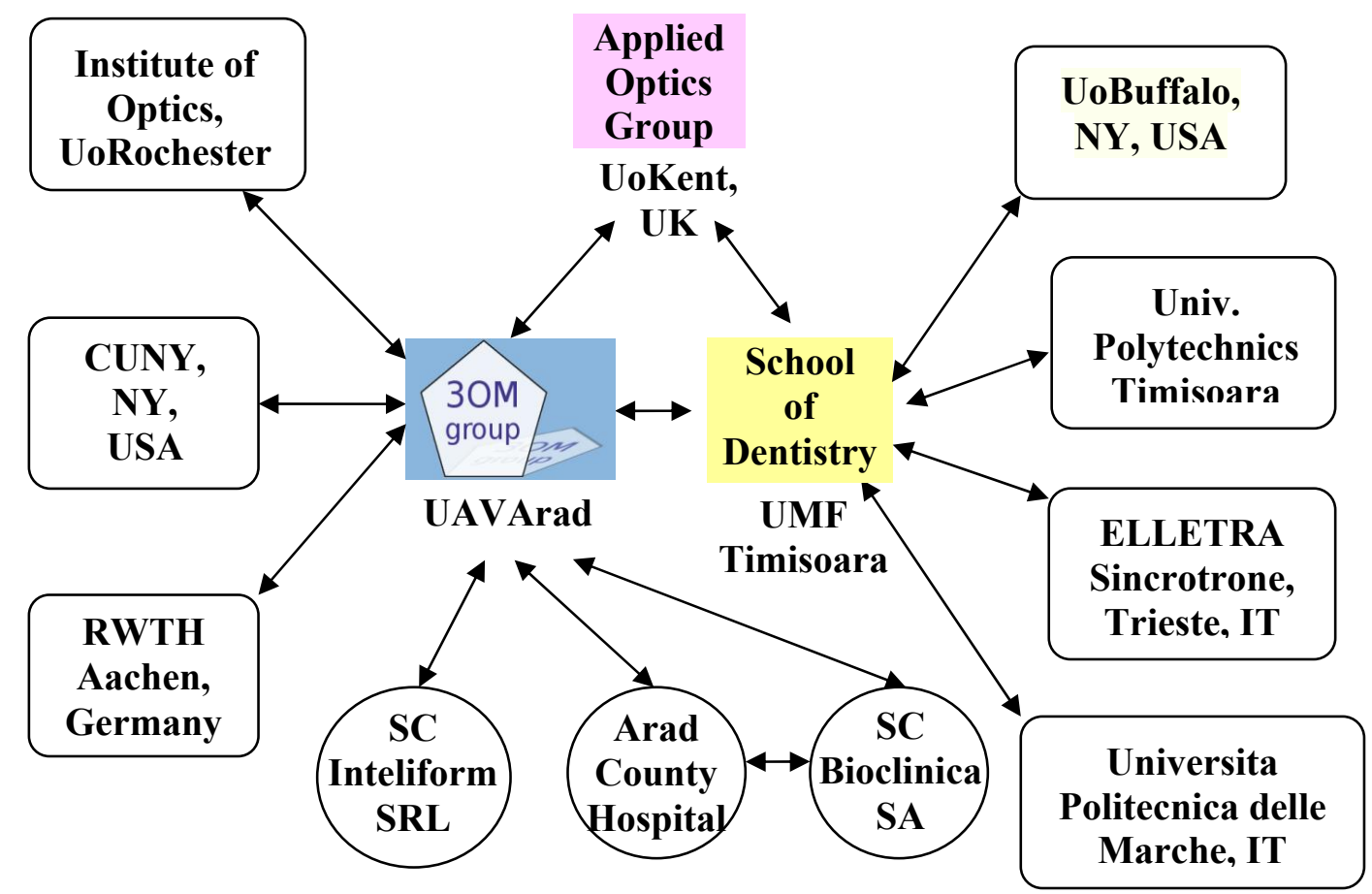

Figure 1. Members of our Consortium and some of their collaborative links. Member institutions from the academia are marked with rectangles, while industrial and medical partners are marked with circles. The central part of the figure comprises the future planned Photonics Pole in Western Romania.

Our Consortium, which we make efforts to continously expand, now comprises several insitutions (Fig. 1). It has been built on an initial collaboration between three groups, located in three universities: 
(1) The Applied Optics Group (AOG) of the University of Kent at Canterbury (UoKent), UK [1], led by Professor A. Gh. Podoleanu, with expertise in Optics and Photonics, focused on Biomedical Imaging and more specifically on Optical Coherence Tomography (OCT);

(2) The Imaging Group [2] of the School of Dentistry, Victor Babes Medicine and Pharmacy University of Timisoara, active, besides the Medical fields, in various areas of Biomedical Imaging applied for Dentistry, but also for other fields such as Materials Studies, including OCT;

(3) The 3OM Group (in Optomechatronics, Optical Metrology, Optics \& Mechanics) [3], School of Engineering, Aurel Vlaicu University of Arad, group established more recently, in 2008 and led by Prof. V.F. Duma, PI of our current Partership Project [4] on which we are trying to put a base to the Photonics Pole in Western Romania.

The industrial and medical partners of our Consortium are also pointed out in Fig. 1 (in circles), while some of our most important collaborators are also shown, in rectangles, with only some of the current collaborative links that exist between them.

\section{CURRENT PARTNERSHIP PROJECT}

In Fig. 2 the general plan of the collaboration in the current project [4] is presented, with some of the tasks assigned to each institution. All of them imply both senior and young researchers. From more than 30 researchers currently involved in the project, almost half are PG and UG students - with the stress on the formers. This human resource that we try to keep balanced is enhanced by the researchers and PG students that are working occasionally on the topics approached by our collaborators (Fig. 1), so the number of people involved is actually variable every month.

The training of these PGs is therefore a challenge [5], especially since they have to move occasionally from one institution to another, and there are various aspects they have to approach by working in small groups at a time. These aspects are covered normally by the coordinator of the project at each institution, but even that has in this case not proved sufficient, and therefore we have designated actually a deputy for each coordinator to be able to face the very diverse tasks that appear. For such a multidisciplinary work, one has to learn not only the scientific component, but also components related to the management of the activities - and this happens at all levels.

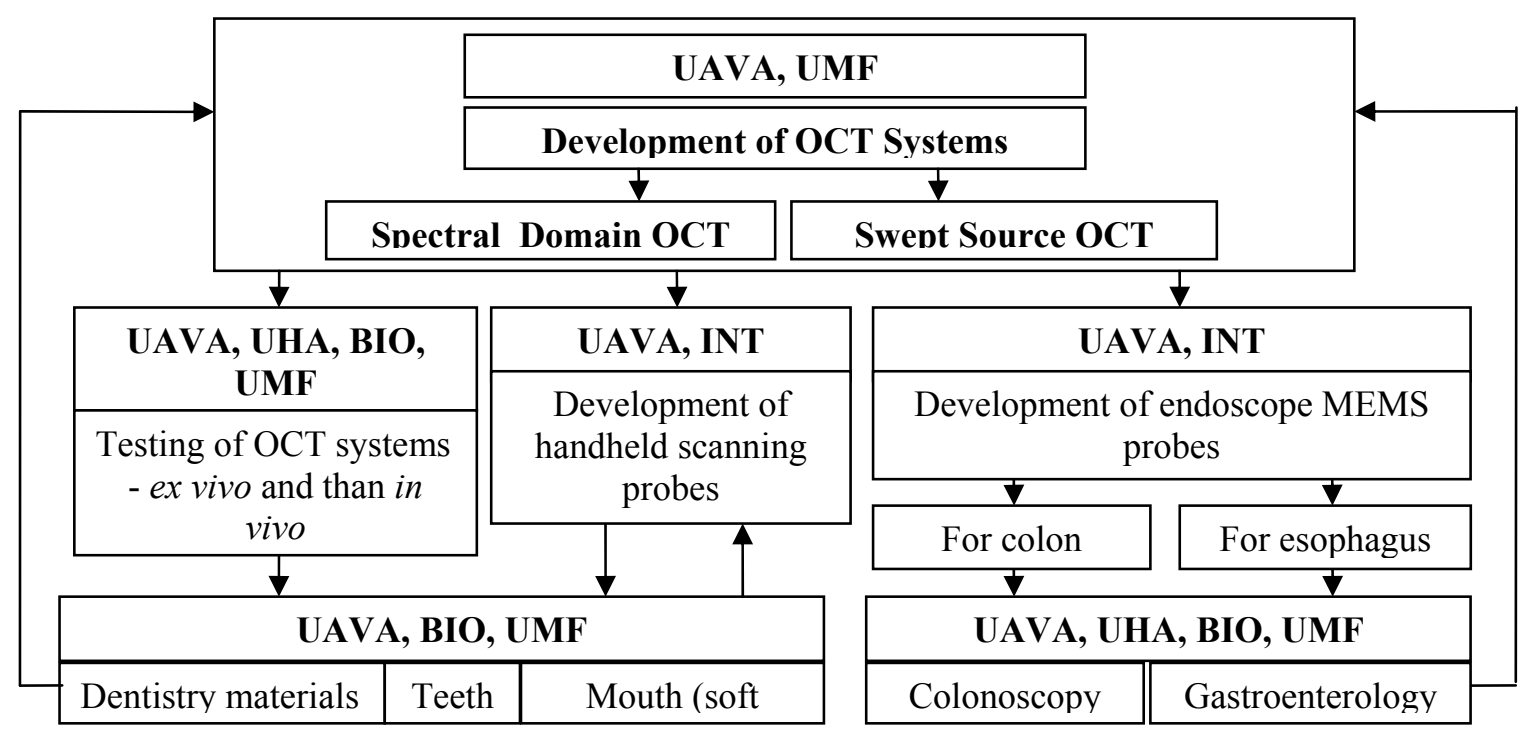

Figure 2. Scheme of the links between the Phases of our current Partnership Project [2] - with the partners involved: UAVA - Aurel Vlaicu University of Arad, UMF - Victor Babes Medicine and Pharmacy University of Timisoara, BIO Biomedica S.A., UHA - University Emergency Hospital of the Arad County, INT - Inteliform S.R.L. Timisoara. 
Although the project has started for less than a year, most of the PG and UG students involved have participated in a conference related to the topics approached - and this has been a specific part of our strategy for their development. For some of them (maily for the UGs) attending this conference has been a very early research experience, while for some of them (even for some PGs) it was the first time that they participated in an international conference (the LASER Congress in Munchen was such a conference). This prepares the ground for more complete journal papers to conclude their various directions of work - from optomechatronics to automation, medicine (endoscopy, gastroenterology) and dentistry (with various aspects, from materials studies in prosthetics to the imaging of the soft tissue of the mouth). It provides the students with a feedback on the level of their work, while also giving them the right image on what the (expected) level of the reseach is internationally. The three years time interval of the project are planned to allow for the complete development of each research theme, but we have verified in practice that a good start is a must for success.

Another most interesting aspect of PG training in our Consortium - particularly, but not only on this project - is the fact that the students (but the seniors as well) come into contact with aspects well outside their usual area of expertise. Thus, everyone has to learn and to expand his/her view to an inter-disciplinarity that may prove quite useful in their future or current carreer.

\section{R\&D, TRAINING AND TEACHING RELATED TO RESEARCH AT EACH PARTNER}

(a) The 3OM Optomechatronics Group at the Aurel Vlaicu University of Arad. Our activity, mainly focused on Optomechatronic devices and systems, is presented in detail in [6]. These research directions include:

(i) Optomechanical choppers [7-9], for which we developed the analysis and design of classical chopper wheels with windows with linear edges [10], introduced and developed a new device, the "eclipse chopper", with wheels with windows with semi-circular edges [11], built prototypes [12], and developed a program for their design (for top-hat, Gaussian and Bessel beams), to chose the parameters of the device in order to obtain a desired profile of the output laser impulses [13];

(ii) Laser scanners: monogon [7, 14, 15]; polygonal [14, 16], which we have analysed [17]; galvanometerbased $[18,19]$, for which we demonstrated $[20,21]$ the optimal scanning functions to be used (which has to be linear plus parabolic [20], not linear plus sinusoidal, as previously stated in literature [19]), and for which PG (and UG) students are working on a variety of topics including optimal control architecture [22,23] and driving algorithms; Risley prisms [24-26], on which student projects are studying their exact patterns [27], as well as driving solutions;

(iii) Radiometry of optical systems [28], including optical attenuators [29], as well as colorimetry;

(iv) Optical metrology - for industrial measurements [30], with on-going UGs projects [15, 31];

(v) OCT [32,33] and related subassemblies [34, 35] - including swept laser sources scanned in frequency [36-38], 2D scanners with galvoscanners [39-41] or with other 1-D devices [42, 43]), and the lateral scanning in OCT, for which we extracted the necessary rules of thumb to use optimally the GSs in OCT setups - and demonstrated that the most artifact-free images are obtained with triangular scanning [44].

For our current project we approach GS-based handheld probes [45], as well as endoscopic miniature scanning heads. Another research avenue is on the optimal scanning algorithms that have to be employed in OCT (but more general, in Biomedical Imaging) to obtain the most - in terms of speed (for in vivo real-time imaging) and artifact-free images from the OCT systems. The translation of the research-gained expertise in UG teaching has been presented in detail in [5], while a most extended discussion on the methodological aspects has been done in [46].

(b) The Imaging Group [2] of the School of Dentistry, Victor Babes Medicine and Pharmacy University of Timisoara is focused on several applications of biomedical imaging techniques for the study of both soft and hard tissue [47], as well as for prosthesis (Fig. 3) and materials used in dentistry. OCT investigations (with Time Domain and Spectral Domain systems) are also validated using other techniques, such as MicroCT (Computer Tomography) - in collaboration with Syncrotron-Radiation Elettra Trieste, X-rays and ultrasounds, but also with hystopathological interpretations. The projects carried out, like our current one [4] involve PG training, while the research results are usually translated into UG teaching - with hands-on-experience.

(c) The Applied Optics Group (AOG) of the University of Kent, UK [1], led by Professor A. Gh. Podoleanu has built up an international reputation based on its extensive publication record in the areas of theoretical and applied optics, and has attracted considerable funding from the EPSRC, BBSRC, Leverhulme Trust, ERC, EC, NIHR, Pfizer, OTI Inc. Canada, New York Eye and Ear Infirmary (NYEEI) and Innovative Small Instruments. 


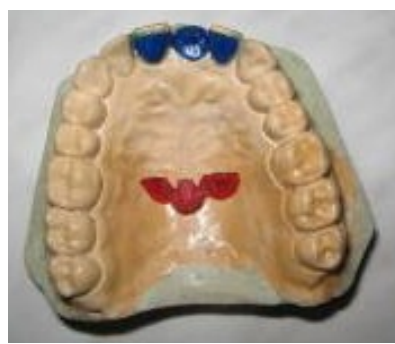

(a)

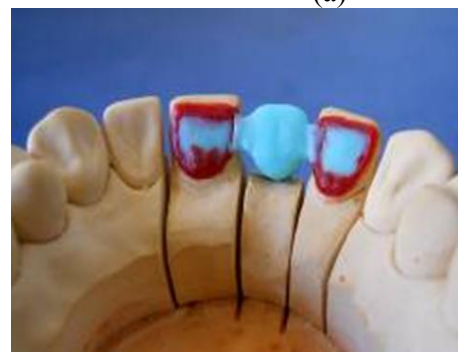

(d)

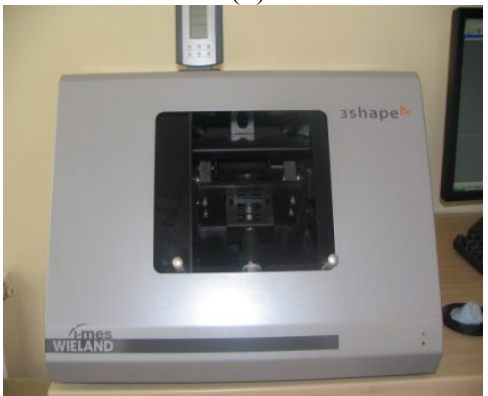

(h)

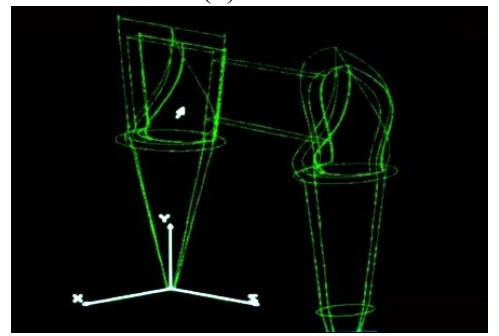

(k)

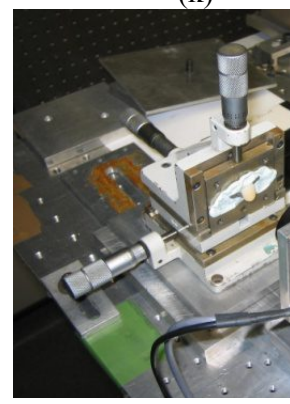

(n)

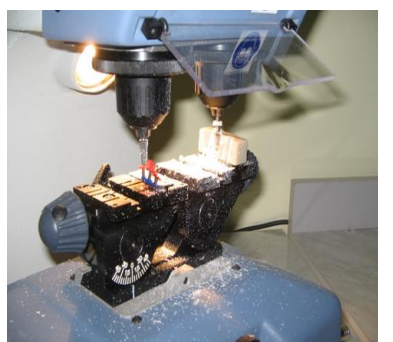

(b)

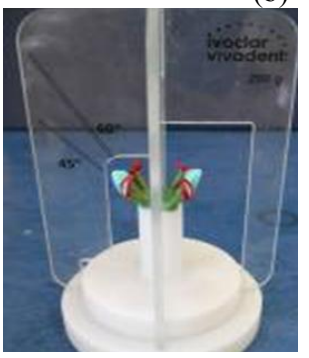

(e)

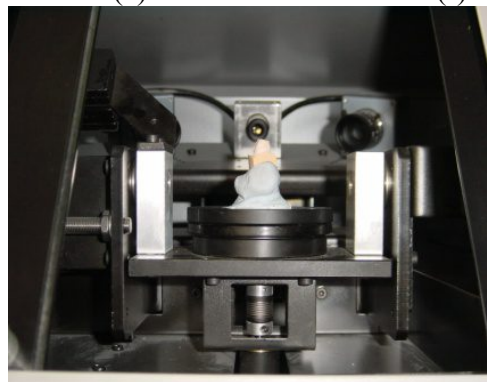

(i)

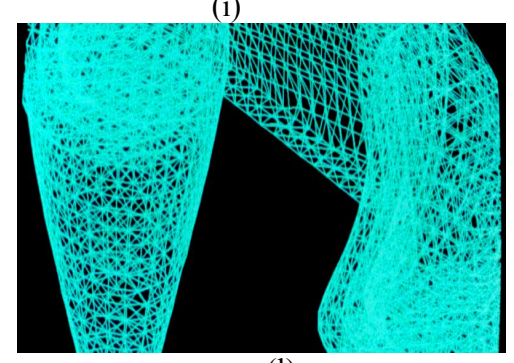

(1)

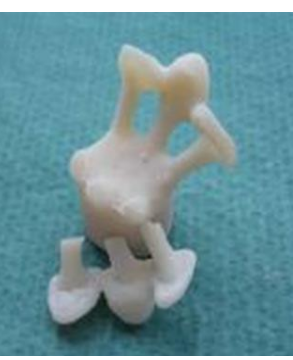

(f)

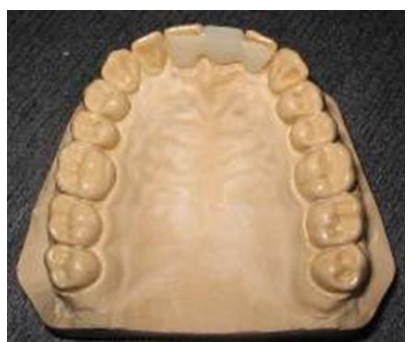

(c)

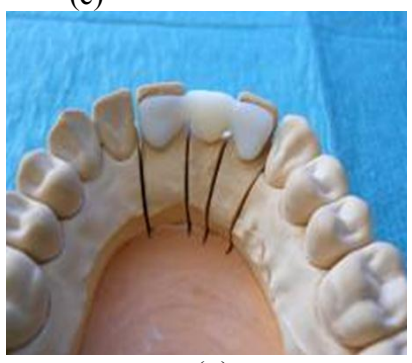

(g)

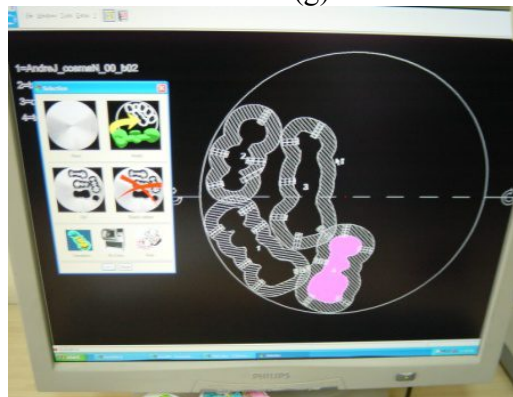

(j)

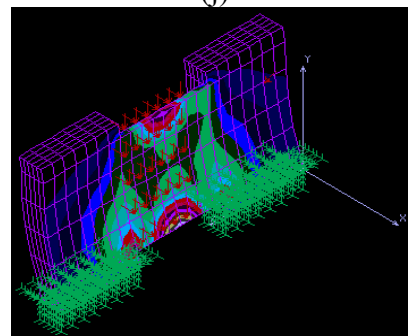

(m)

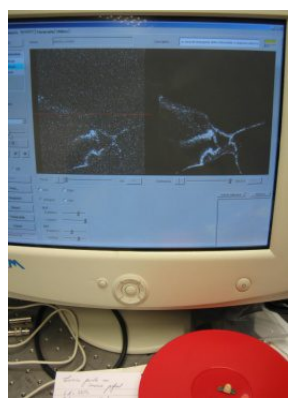

(o)

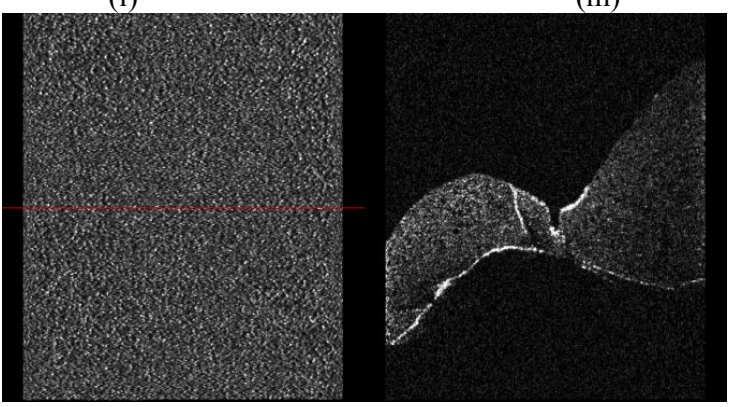

(p)

Figure 3. Technological approach of the fixed partial prosthesis: after modelling a RBFPD from a special composite resin (a) and the parallel mechanical milling by a dedicated system (Dakar) (b) in order to obtain the final aspect of the integral ceramic fixed partial prosthesis (c); wax modeling of RBFPD for the pressing technology (d); the wax infrastructure ready for investment (e) and pressing technology (f); CAD/CAM technology for the same integral ceramic fixed partial prosthesis $(h, i, j)$; numeric simulations of the same integral ceramic bridge to observe the most tensioned area of the structure $(\mathrm{k}, 1, \mathrm{~m})$ and OCT investigation of the areas with the fracture line discovered inside the ceramic material. 
The AOG has pioneered en face Optical Coherence Tomography (OCT) technology in 1996 and has produced the first OCT en face images from the retina, has researched and protected the generation of a combined OCT / confocal image [48], generated 3D images from retina and skin, devised multi-interferometer configurations and special modulators to collect simultaneously images from different depths in the tissue and introduced the concept of OCT imaging with adjustable depth resolution. AOG also performed theoretical studies on the performances of OCT systems. First images of eye with pathologies using en-face OCT have been reported. AOG has also developed the first instrument combining OCT with ICG fluorescence for imaging the retina in collaboration with New York Eye and Ear Infirmary and Ophthalmic Technology Inc. Combination of three technologies in one system, OCT, scanning laser ophthalmoscopy and adaptive optics and highest limit in vivo obtained in en-face images as thin as $3 \mu \mathrm{m}$ were reported. Resources were oriented towards extending the expertise acquired from ophthalmology to cell imaging and OCT applicability to image embryos [49] and more recently, towards OCT endoscopy [45]. Expertise was extended to dentistry [47], to imaging of basal cell carcinoma and to art conservation [50]. Other current research focuses on a novel solutions to reject the effect of mirror terms in spectrometer based OCT [51], to eliminate the speckle in OCT, to perform 3D imaging using multiple paths configurations [52, 53], on coherence gated wavefront sensors [54] and on speeding up the acquisition based on graphics cards [55].

Professor Podoleanu has been involved in supervision of postdoctoral researchers constantly from 1999, with a number fluctuating, up to 5/year and of PhD students, with a number up to 8/year. He has created a new lecture course, required to be taught to students recruited by a Marie Curie Training site, HIRESOMI (2006 - 20010) he has coordinated with two other universities and three companies in Europe, supported by the EC, Biomedical Optic. This is now being taught to other PhD students in the School of Physical Sciences in the UoKent. Research inspired undergraduate projects are conducted by the AOG with students from the $3^{\text {rd }}$ year MSc (PH600) and $4^{\text {th }}$ year MPhys $(\mathrm{PH} 700)$ in the School of Physical Sciences. They cover several aspects of applied optics, such as designing hand held probes for imaging the eye, for imaging in the mouth, for endoscopy and addressing fundamental limits in the technology, such as devising simple methods for linearisation of data before FFT [56]. An applied optics project is conducted with students from the $3^{\text {rd }}$ year Forensic Science programs on investigating the OCT as an anti-spoof tool in imaging fingerprint at security points. Other projects are conducted with students from other universities in the South East of England, supported for short summer projects by South East Physics Network (SEPNET), embracing assembly of optical configurations for OCT as well as devising customised LabView Matlab programmes for OCT interfaces. AOG is also regularly acting as host of Erasmus work placement students, sent by Universities in Brno, Lille and Porto for $3-10$ months to develop practical skills in an optics lab. Such exchanges resulted in published results in journals [57] and several conferences.

(d) The Optical Diagnostics and Applications Lab (ODALab) [58], founded in 1994 by Professor Jannick Rolland, is today comprised of distributed labs. Its headquarter is at The Institute of Optics, University of Rochester (UoR), NY USA, and it has two satellite labs, one at the University of California at Los Angeles (UCLA), led by Dr. Anand Santhanam, and the other at Armstrong Atlantic University in Georgia, led by Dr. Felix Hamza-Lup. The research at UCLA focuses on Augmented Reality (AR) in the context on radiation oncology together with GPU-based processing for clinical translation, while the satellite lab in Armstrong Atlantic University focuses on undergraduate and master education in augmented reality, wth a focus on haptic and networking AR. The research in the headquarter lab focused early on solely on novel head-worn displays for AR [59-61]. The ODALab conducted some of the first depth perception studies in AR environments published in the Journal Presence: Teleoperators and Virtual Environments (MIT Press) [62-64]. Around 2000, the research expanded to include research in optical imaging, such as in Optical Coherence Toomography (OCT). This area of research has bloomed to an active area of research in the ODALab, focused on instrumentation development for high lateral-resolution imaging across extended depth-of-focus via Bessel Beam Imaging [65] and Gabor Domain Optical Coherence Microscopy (GD-OCM) [66-72]. GD-OCM operates at higher numerical aperture than OCT, leverages liquid lens technology within a custom imaging microscope [67-68], and processes images using a Gabor-based fusion technique [69]. It achieves micrometer-class lateral resolution over up to two milimeter in depth for skin tissue [71-72]. The lab also focuses on advances in functional OCT such as Doppler OCT [73-74] and OCT elastogrpahy. The ODALab partners with Medical Centers to conduct research related to the upper airways, the human eye, skin and the oral cavity.

Since 2007, research in the ODALab started focused efforts in freeform optics driven by critical needs in compact and mobile instrumentation, specifically, in the applications of AR [75-76] and biomedical research. Several national and 
international sponsors, collaborators and industrial partners participate in the research efforts. Support is given through grants from the National Science Foundation, the NYSTAR Foundation, the II-VI Foundation, government research labs and industry. As part of a growing interest in freeform optics [77], Prof. Rolland is currently the director of a planned NSF Center for Freeform Optics, collaboration between UoR and the University of North Carolina Charlotte.

In terms of UG students at the University of Rochester, there is a Journal of Undergraduate Research (JUR), entirely focused on publishing peer-review articles, from all domains, but only from UG students. Also, some half of the UG and most PG (Master) students are implied in research. Prof. Rolland, by example, is the Director of the Robert E. Hopkins Center for Optical Design an Engineering that was created to provide students with a computer lab, a fabrication lab, and a testing lab, that all, from UG to PG can access to develop hands on experience. Activities with the Center are integrated as part of lectures to provide a place for experiencing hands on learning. Also several classes have a lab component to give students hands-on experience with knowledge taught in the classroom.

Training of PG (Doctoral students, but also PostDocs and Master students) is an essential component of the ODALab activity, and the funding discussed previously is focused to support their activity. There are thus up to 20 young researchers at a time in Prof. Rolland's supervision - over half are Ph.D. students.

The collaboration of the Consortium with ODALab has started in 2009, when Prof. Duma (UAVA) was a Fulbright Senior Research Fellow at The Institute of Optics, University of Rochester, in Sept. 2009-June 2010. It continues on issues of scanning in OCT [35], especially for galvoscanners [44], as well as on various problems of optical engineering.

(e) The Nanofabrication Facility at the Grove School of Engineering of the City University of New York (CUNY), NY, USA.

The activity in the Nanofabrication Facility is focused on the design, manufacturing and testing of Micro-ElectricalMechanical Systems (MEMS). The collaboration of the Facility with the Consortium (Fig. 1) is focused on the manufacturing and testing of MEMS for different types of endoscopes for OCT.

In terms of teaching, the main interests of the Facility head, Prof. Ioana Voiculescu are to teach the students at UG and PG about emerging technologies. The emergence of new technologies that are revolutionizing the practice of engineering, the miniaturization of mechanical device, the advent of nanotechnology, the emergence of intelligent systems, the introduction of new and advanced materials, the development of sophisticated software and finally the revolution in biology are the base for modeling a modern curriculum in the Mechanical Engineering studies [79]. Based on these considerations the teaching is focused on the study of MEMS technology with a focus on optics applications. For the study of MEMS device a special commercial chip named Class on Chip (Class on a Chip, Inc., TX, USA) [80] is used. This chip is based on MEMS devices and provides innovative educational and research platforms for students at UG and PG level. This silicon chip has the dimensions $6.3 \mathrm{~mm} \times 2.8 \mathrm{~mm}$ and contains 16 devices that move, allowing a wide range of experiments to be conducted. Several devices contain micromirrors (Fig. 4d). In the application from Fig. 4a-c the students learn the process to fabricate micromirrors; they can also analyze with the microscope the micromirror and the mechanical system used to actuate the micromirror. After the students are familiar with the concept of micromirror they are asked to find papers related to this topic and each student will have a short presentation of the paper selected by the student on micro-mirrors fabrication process and applications.

The applications in the industrial sector are increasing. There are several possible applications for MEMS and Nanotechnology in various fields like biotechnology (ex: biochips for detection of hazardous chemical and biological agents), medicine (MEMS pressure sensors) or communication (circuit) [81]. MEMS have a lot of advantages: small size and small scale allow to place a lot of different devices on the same system; it is also less expensive because we minimize the materials consumption used to make MEMS. With this kind of system you can transfer a small motion on nano-scale to a bigger motion on the macro-scale.

(f) Arad County Emergency University Hospital applies the OCT systems at the partners in conjunction with the handheld and endoscope scanning probes that we are developing in the project. Thus, the Department of Gastroenterology is using the equipments in gastroenterology and in colonoscopy - with endoscopic investigations. The Department of Pathological Anatomy performs the necessary histological analysis to provide the calibration of the technique and the necessary feed-back for validation of the OCT results. 


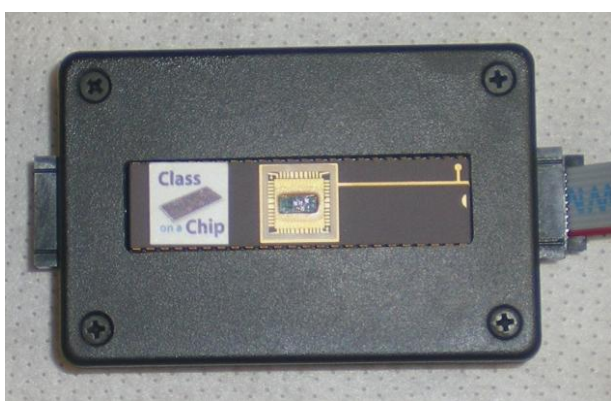

(a)

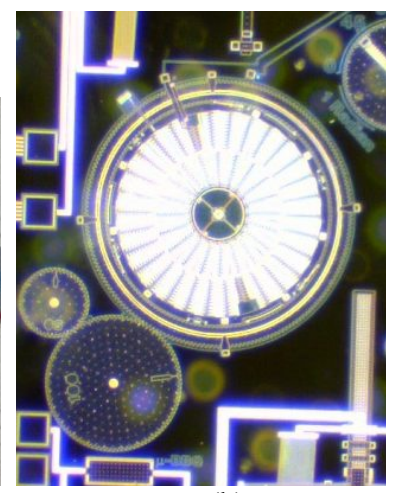

(b)

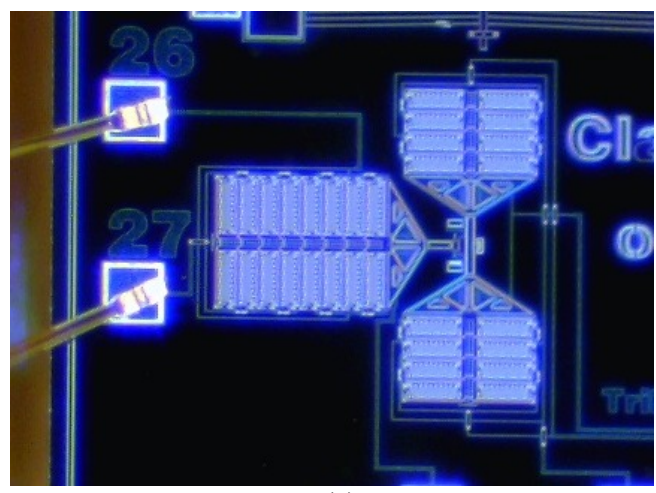

(c)

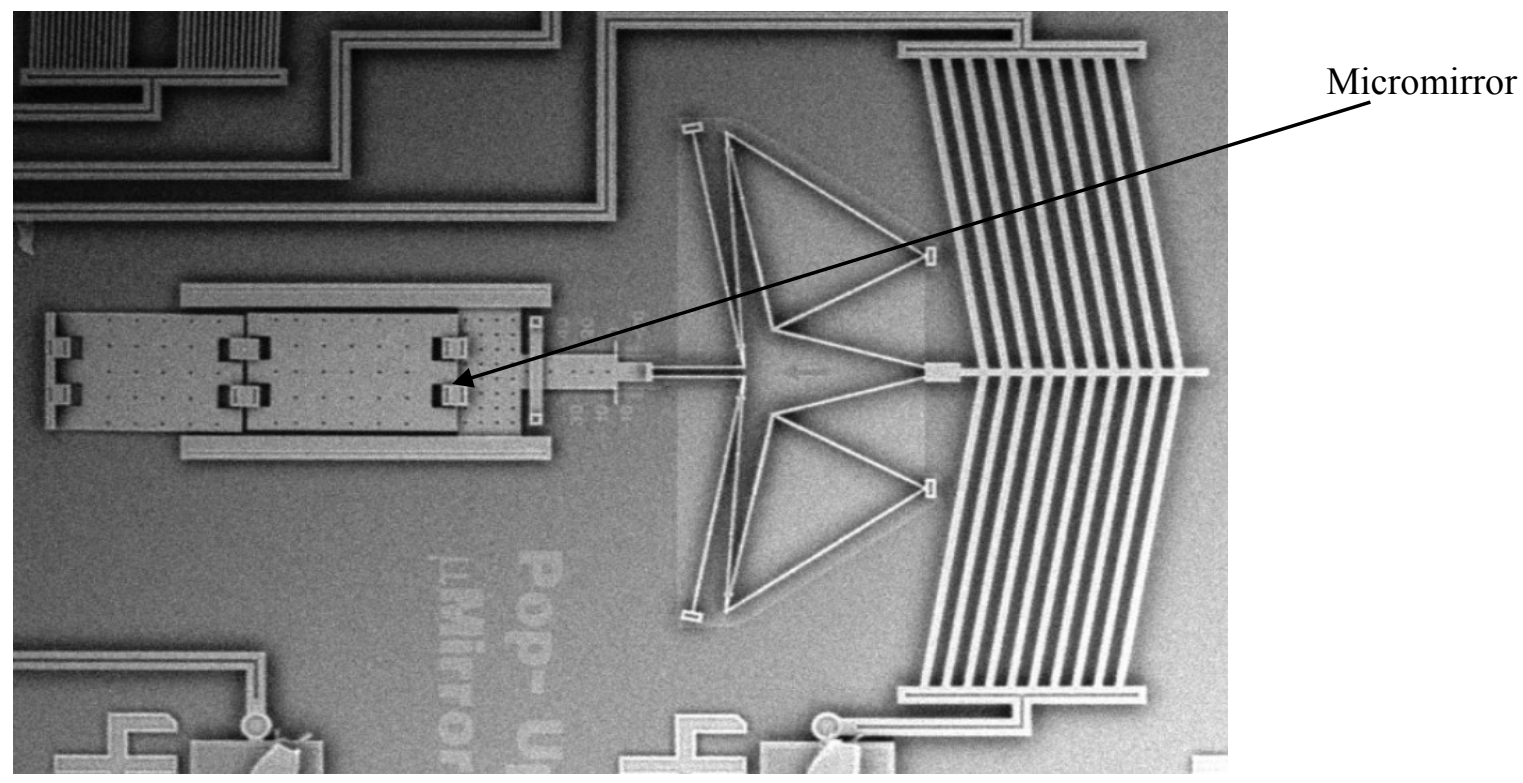

Figure 4. Lab-on-a-chip [65] used for MEMS teaching at the City University of New York (CUNY), NY, USA: (a) view of the chip mounted; (b) micro-motor and gears whithin the chip; (c) comb-drivers; (d) Micromirror MEMS structure on chip for student education with microstructures for optical applications.

The investigation itinerary is the normal one, as biological samples are first studied in vitro, and after the calibration, in vivo. We expect that at the end of the project the OCT equipments (system \& different scanning probes) will be ready to move from lab to the clinic environment. Among the research objectives targeted there are: Barrett's esophagus and the investigation or the removal (endoscopically) of polypoid lesions. One has to stress that traditional procedures such as Ultra-magnifying Endocytoscopy, Autofluorescence Imaging, Chromoendoscopy or Confocal Laser Endomicroscopy have important advantages: they reduce unnecessary biopsies or resections, and they therefore decrease the risk of endoscopic complications. Their drawbacks (high costs, labor intensive, time consuming, and need experienced MDs) imposes OCT as a valuable tool for investigations. OCT will be used to by example to differentiate between neoplastic and non-neoplastic lesions, and to increase the accuracy of the differential diagnosis, as in colon adenoma.

(g) S.C. Inteliform S.R.L. Timisoara is a dynamic SME focused on Mechanical Engineering and Mechatronics, but also on Optical Engineering and Optomechanics. With 60+ employees, from which 16 are engineers, it was and is involved in several R\&D projects. Its main activity is in the design, simulations and manufacturing of very diverse pieces and systems. In the Consortium it achieves the technology and manufacturing of prototypes. It also provides - at least in part - the technological transfer of the results obtained through research. 


\section{CONCLUSIONS}

The paper presents our Consortium, our main collaborators [1, 2], our current Partnership Project [4] and some of its challenges. A few aspects related to the necessary interactions between universities and industry in our Consortium (and to the role of the later) were also pointed out. These efforts are part of a longer term strategy that aims to create the structure of a future Photonics pole in Western Romania.

Issues and activities related to the training of postgraduate (PG) students and to the teaching of undergraduate (UG) students (and to the translation of the research experience for the teaching process) are pointed out - at the academic partners. This paper completes - in terms of a collaborative structure - the presentation made on these aspects in [6] for the activity of the 3OM Optomechatronics Group [3].

Future work comprises further translation of the research results and expertise into the UG and Master curricula, the enhancement of our early research experinece with UGs, and a better training of the PG, especially at Doctoral and PostDoc level, with a focus on driving them towards higher impact research - and publications - at an as-early-aspossible stage of their work.

Directions of development of the Photonics Pole structure are also envisaged, with the inclusion of other partners from the region and with the enhancement of the collaborations with our partners from Europe and USA. There is also a continuous, natural effort to attract significant funding for the development of our activities in $R \& D$ and to its applications in industry and medicine.
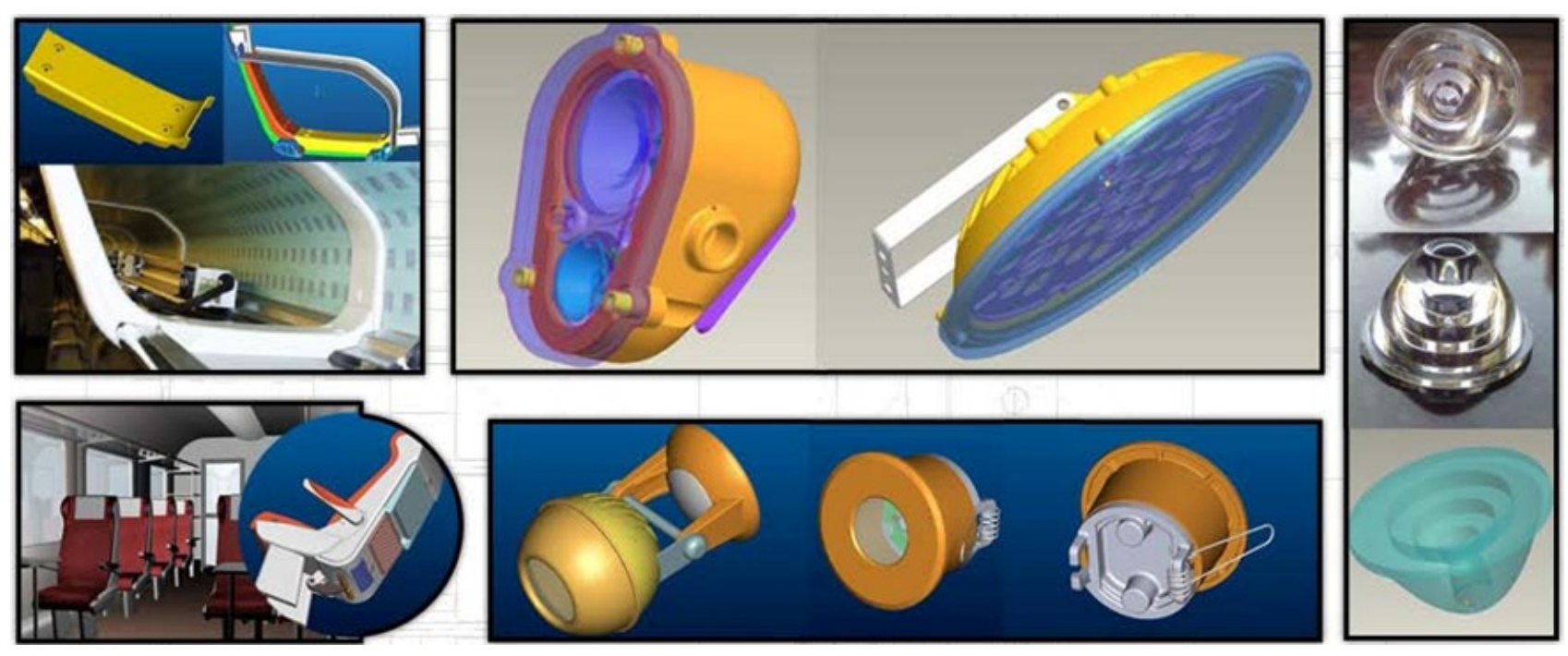

Figure 5. S.C. Inteliform S.R.L. Timisoara - examples of plastic molded parts (including optical) designed and fabricated.

\section{ACKNOWLEDGMENTS}

This work was supported by a Partnership grant of the Romanian National Authority for Scientific Research, CNDIUEFISCDI project number PN-II-PT-PCCA-2011-3.2-1682. A. Gh. Podoleanu acknowledges the ERC $7^{\text {th }}$ Framework Programme, Advanced Grant 'COGATIMABIO' 249889 and the NIHR Biomedical Research Centre at Moorfields Eye Hospital NHS Foundation Trust and UCL Institute of Ophthalmology.

\section{REFERENCES}

[1] http://www.kent.ac.uk/physical-sciences/research/aog/index.html

[2] http://www.umft.eu/md_210

[3] www.3omgroup.appspot.com/

[4] http://3om-group-optomechatronics.ro/ 
[5] Duma, V. F., Negrutiu, M. L., Sinescu, C., Voiculescu, I., Miutescu, E., Burlea, A., Vlascici, M., Podoleanu, A. Gh., "Research lead student projects on multi-disciplinary optomechatronics with applications in biomedical imaging," New Trends in Educational Activity in the Field of Mechanism and Machine Theory 19, 145-153 (2013).

[6] Duma, V. F., Mnerie, C., Demian, D., Hutiu, G., and Kaposta, I., "Building an Optomechatronics Group in a young university in Western Romania," Proc. SPIE ET100, ET100-93 (2013).

[7] Marshall, G. F., [Handbook of Optical and Laser Scanning], Marcel Dekker, New York, 417-476 (2004).

[8] McDermid, I. S., Beyerle, G., Haner, D. A., and Leblanc, T., "Redesign and improved performance of the tropospheric ozone lidar at the jet propulsion laboratory table mountain facility," Applied Optics 41, 7550-7555 (2002).

[9] He, Y., Jin, W., Liu, G., Gao, Z., Wang, X., and Wang, L., "Modulate chopper technique used in pyroelectric uncooled focal plane thermal imager," Proc. SPIE 4919, 283-288 (2002).

[10] Duma, V. F., "Theoretical approach on optical choppers for top-hat light beam distributions," J. of Optics A: Pure and Applied Optics 10, 064008 (2008).

[11] Duma, V. F., "Optical choppers with circular-shaped windows: Modulation functions," Communications in Nonlinear Science and Numerical Simulation 16(5), 2218-2224 (2011).

[12] Duma, V. F., "Prototypes and modulation functions of classical and novel configurations of optical chopper wheels," Latin American Journal of Solids and Structures 10(1), 5-18 (2013).

[13] Cira, O. and Duma, V. F., "Transmission functions of optical choppers for Gaussian beam distributions: Modeling and simulations," Proc. SPIE 8789, 87890E (2013).

[14] Marshall, G. F., [Handbook of Optical and Laser Scanning], CRC Press, New York (2011).

[15]Duma, V. F., "On-line measurements with optical scanners: metrological aspects," Proc. SPIE 5856, 606-617 (2005).

[16] Beiser, L., "Design equations for a polygon laser scanner," Proc. SPIE 1454, 60-66 (1991).

[17] Duma, V. F., "Novel approaches in the designing of polygon scanners," Proc. SPIE 6785, 6785-1Q (2007).

[18] Aylward, R. P., "Advances and technologies of galvanometer-based optical scanners," Proc. SPIE 3787, 158-164 (1999).

[19] Montagu, J., "Scanners - galvanometric and resonant," Encyclopedia of Optical Engineering, 2465-2487 (2003).

[20] Duma, V. F., "Optimal scanning function of a galvanometer scanner for an increased duty cycle," Optical Engineering 49(10), 103001 (2010).

[21] Duma, V. F., "Command functions of open loop galvanometer scanners with optimized duty cycles," Theoretical and Applied Mechanics Letters 2(4), 043005 (2012).

[22] Duma, V. F. and Mnerie, C., "Optimization of scanning and command functions of galvanometer-based scanners," Proc. SPIE 8083, 8083-45 (2011).

[23] Mnerie, C., Preitl, S., and Duma, V. F., "Mathematical model of a galvanometer-based scanner: simulations and experiments," Proc. SPIE 8789, 8789-43 (2013).

[24] Yang, Y., "Analytic solution of free space optical beam steering using Risley prisms," J. Lightwave Technol. 26, 3576-3583 (2008).

[25] Warger II, W. C. and DiMarzio, Ch. A., "Dual-wedge scanning confocal reflectance microscope," Opt. Letters 32, 2140-2142 (2007).

[26] Garcia-Torales, G., Strojnik, M. and Paez, G., "Risley prisms to control wave-front tilt and displacement in a vectorial shearing interferometer," Appl. Opt. 41, 1380-1384 (2002).

[27] Schitea, A., Tuef, M., and Duma, V. F., "Modeling of Risley prisms devices for exact scan patterns," Proc. SPIE $8789,8789-40$ (2013).

[28] Duma, V. F., "Radiometric versus geometric, linear and non-linear vignetting coefficient," Applied Optics 48(32), 6355-6364 (2009).

[29] Duma, V. F. and Nicolov, M., "Neutral density filters with Risley prisms: analysis and design,” Appl. Opt. 48, 2678-2685 (2009).

[30] Richter, B., "Laser scan devices for industrial application," WIRE 42(6), 529-540 (1992).

[31] Duma, V. F., "Dimensional measurements with optical scanners," Proc. $4^{\text {th }}$ European Workshop on Structural Health Monitoring (ESHM), 1217-1224 (2008).

[32] Huang, D., Swanson, E. A., Lin, C. P., Schuman, J. S., Stinson, W. G., Chang, W., Hee, M. R., Flotte, T., Gregory, K., Puliafito, C. A., and Fujimoto, J. G., "Optical coherence tomography," Science 254(5035), 1178-1181 (1991). 
[33] Wojtkowski, M., "High-speed optical coherence tomography: basics and applications," Applied Optics 49, D30D61 (2010).

[34] Duma, V.F., "Optomechatronic Modulators: Choppers, Attenuators and Scanners. Analysis and Design," Habilitation Thesis - Polytechnics University of Bucharest (2013).

[35] Duma, V. F., Rolland J. P., and Podoleanu, A. Gh., "Perspectives of optical scanning in OCT," Proc. SPIE 7556, 7556-10 (2010).

[36] Yun, S. H., Boudoux, C., Tearney, G. J., and Bouma, B. E., "High-speed wavelength-swept semiconductor laser with a polygon-scanner-based wavelength filter," Optics Letters 28, 1981-1983 (2003).

[37] Oh, W. Y., Yun, S. H., Tearney, G. J., and Bouma, B. E., "115 kHz tuning repetition rate ultrahigh-speed wavelength-swept semiconductor laser," Opt. Letters 30, 3159-3161 (2005).

[38] Mao, Y., Flueraru, C., Sherif, S., and Chang, S., "High performance wavelength-swept laser with mode-locking technique for optical coherence tomography," Optics Communications 282, 88-92 (2009).

[39] Duma, V. F. and Podoleanu, A. Gh., "Theoretical approach on a galvanometric scanner with an enhanced duty cycle," Proc. SPIE 7139, 71390D (2008).

[40] Li, Y., "Beam deflection and scanning by two-mirror and two-axis systems of different architectures: a unified approach," Appl. Opt. 47, 5976-5985 (2008).

[41] Duma, V. F., "Mathematical Functions of a 2-D Scanner with Oscillating Elements," Modeling, Simulation and Control of Nonlinear Engineering Dynamical Systems, 243-253 (2009).

[42] Kim, K. H., Buehler, C., and So, P. T. C., "High-speed, two-photon scanning microscope," Appl. Opt. 38, 60046009 (1999).

[43] Duma, V. F. and Podoleanu, A. Gh., "Polygon mirror scanners in biomedical imaging: a review," Proc. SPIE 8621, $8621 \mathrm{~V}(2013)$.

[44] Duma, V. F., Lee K.-S., Meemon P., and Rolland, J. P., "Experimental investigations of the scanning functions of galvanometer-based scanners with applications in OCT," Applied Optics 50(29), 5735-5749 (2011).

[45] Cernat, R., Tatla, T. S., Pang, J., Tadrous, P. J., Bradu, A., Dobre, G., Gelikonov, G., Gelikonov, V., and Podoleanu, A. Gh., "Dual instrument for in vivo and ex vivo OCT imaging in an ENT department," Biomed. Opt. Express 3, 3346-3356 (2012).

[46] Duma, V. F., "Teaching Mechanisms: from Classical to Hands-on-Experiments and Research-Oriented," Mechanisms and Machine Science 5(8), 493-501 (2010).

[47] Sinescu, C., Negrutiu, M. L., Todea, C., Balabuc, C., Filip, L., Rominu, R., Bradu, A., Hughes, M. and Podoleanu, A. Gh., "Quality assessment of dental treatments using en-face optical coherence tomography," J. Biomed. Opt. 13(05), 054065 (2008).

[48] Podoleanu, A. Gh. and Rosen, R. B., "Combinations of techniques in imaging the retina with high resolution," Progress in Retinal and Eye Research 27, 464-499 (2008).

[49] Ma, L., Bradu, A., Podoleanu, A. Gh., and Bloor, J. W., "Arrhythmia Caused by a Drosophila Tropomyosin Mutation Is Revealed Using a Novel Optical Coherence Tomography Instrument," PLoS 5(12), 1-8 (2010).

[50] Liang, H., Cid, M. G., Cucu, R. G., Dobre, G. M., Podoleanu, A. Gh., Pedro, J., and Saunders, D., "En-face optical coherence tomography - a novel application of non-invasive imaging to art conservation," Opt. Express 13(16), 6133-6144 (2005).

[51] Podoleanu, A. Gh., "Unique interpretation of Talbot bands and Fourier domain white light interferometry," Opt. Express 15(15), 9867-9876 (2007).

[52] Rogers, J. A., Bradu, A., and Podoleanu, A. Gh., "Polarization maintaining multiple-depth en face optical coherence tomography system using active re-circulation loops in the non-stationary state," Opt. Express 20, 29196-29209 (2012).

[53] Zurauskas, M., Rogers, J., and Podoleanu, A. Gh., "Simultaneous multiple-depths en-face optical coherence tomography using multiple signal excitation of acousto-optic deflectors," Opt. Express 21, 1925-1936 (2013).

[54] Wang, J. and Podoleanu, A. Gh., "Demonstration of real-time depth-resolved Shack-Hartmann measurements," Opt. Letters 37(23), $4862-4864$ (2012).

[55] Van der Jeught, S., Bradu, A., and Podoleanu, A. Gh., "Real-time resampling in Fourier domain OCT using a graphics processing unit," JBO Letters 15, 030511 (2010).

[56] Payne, A. and Podoleanu, A Gh., "Direct electronic linearization for camera-based spectral domain optical coherence tomography," Opt. Letters 37(12), 2424-2426 (2012).

[57] Bouchal, P., Bradu, A., and Podoleanu, A. Gh., "Gabor fusion technique in a Talbot bands optical coherence tomography system," Opt. Express 20(5), 5368-5383 (2012). 
[58] http://www.odalab-spectrum.org

[59] Robinett, W. and Rolland, J. P., "A computational model for the stereoscopic optics of a head-mounted display," Presence: Teleoperators and Virtual Environments (MIT Press), 1(1), 45-62 (1992).

[60] Rolland, J. P., "Wide angle, off-axis, see-through head-mounted display," Optical Engineering 39(7), 1760-1767 (2000).

[61] Cakmakci, O. and Rolland, J. P., "Head-worn displays: A review," IEEE/OSA Journal of Display Technology, 2(3) 199-216 (2006).

[62] Rolland, J. P., Ariely, D., and Gibson, W., "Towards quantifying depth and size perception in virtual environments," Presence: Teleoperators and Virtual Environments 4(1), 24-49 (1995).

[63] Rolland, J. P., Meyer, C., Arthur, K., and Rinalducci, E., "Methods of adjustments versus method of constant stimuli in the quantification of accuracy and precision of rendered depth in head-mounted displays," Presence: Teleoperators and Virtual Environments 11(6), 610-625 (2002).

[64] Biocca, F. and Rolland, J. P., "Virtual eyes can rearrange your body: adaptation to virtual eye location in see-thru head-mounted displays," Presence: Teleoperators and Virtual Environments 7(3), 262-277 (1998).

[65] Lee, K.-S. and Rolland, J. P., "Bessel-Beam Spectral-Domain High-Resolution OCT with Microoptics Axicon Providing Extended Focusing Range," Optics Letters 33(15), 1696-1698 (2008).

[66] Murali, S., Lee, K.-S., and Rolland, J. P., "Invariant resolution dynamic focus OCM based on liquid crystal lens," Opt. Express $15,15854-15862$ (2007).

[67] Murali, S., Thompson, K. P., and Rolland, J. P., “Three-dimensional adaptive microscopy using embedded liquid lens," Opt. Letters 34, 145-147 (2009).

[68] Murali, S., Panomsak, M., Lee, K.-S., Kuhn, W. P., Thompson, K. P., and Rolland, J. P., "Assessment of a liquid lens enabled in vivo optical coherence microscope," Applied Optics 49(16), D145-156 (2010).

[69] Rolland, J. P., Meemon, P., Murali, S., Thompson, K. P., and Lee, K.-S., "Gabor-based fusion technique for Optical Coherence Microscopy," Opt. Express 18, 3632-3642 (2010).

[70] Lee, K.-S., Thompson, K. P., and Rolland, J. P., "Broadband astigmatism-corrected Czerny-Turner spectrometer," Optics Express 18(22), 23378-23384 (2010).

[71] Lee, K.-S., Thompson, K. P., Meemon, P., and Rolland, J. P., "Cellular resolution optical coherence microscopy with high acquisition speed for in-vivo human skin volumetric imaging," Opt. Letters 36, 2221-2223 (2011).

[72] Lee, K.-S, Zhao, H., Ibrahim, S. F., Meemon, N., Khoudeir, L., and Rolland, J. P., "Three-dimensional imaging of normal skin and nonmelanoma skin cancer with cellular resolution using Gabor domain optical coherence microscopy", J. Biomed. Opt. 17(12), $126006(2012)$.

[73] Meemon, P., Lee, K.-S., and Rolland, J. P., "Doppler imaging with dual-detection full-range frequency domain optical coherence tomography," Biomed. Opt. Express 1(2), 537-552 (2010).

[74] Meemon, P. and Rolland, J. P., "Swept-source based, single-shot, multi-detectable velocity range Doppler optical coherence tomography," Biomed. Opt. Express 1(3), 955-966 (2010).

[75] Cakmakci, O. and Rolland, J. P., "Design and Fabrication of a Dual-Element Off-Axis Near-Eye Optical Magnifier," Optics Letters, (32)11, 1363-1365 (2007).

[76] Cakmakci, O., Moore, B., Foroosh, H., and Rolland, J. P., "Optical local shape description for rotationally non-symmetric optical surface design and analysis," Optics Express 16(3), 1583-1589 (2008).

[77] Thompson, K. P. and Rolland, J. P., "Freeform Optical Surfaces - A Revolution in Imaging Optical Design", Optics and Photonics News p30-37, (June 2012).

[78] Duma, V. F. and Rolland, J. P., "Mechanical Constraints and Design Considerations for Polygon Scanners," Mechanisms and Machine Science 5(8), 475-483 (2010).

[79] Delale, F., Liaw, B.M., Jiji, L. M., Voiculescu, I., and Yu, H., "Infusion of Emerging Technologies and New Teaching Methods into The Mechanical Engineering Curriculum at The City College of New York", Advances in Engineering Education 2(4) (2011).

[80] http://classonachip.com/

[81] Voiculescu, I., Zaghloul, M. E., McGill, R. A., Houser, E. J., and Fedder, G. K., "Electrostatically actuated resonant microcantilever beam in CMOS technology for the detection of chemical weapons," IEEE Sensors Journal 5(4), 641-647 (2005). 